\title{
The Role Of Urban Density And Morphology In The Air Pollution Of Tehran Metropolitan
} Dr. ROUHOLLAH OSHRIEH $1{ }^{1}$, *Dr. EHSAN VALIPOUR ${ }^{2}$

IIslamic Azad University, Tabriz International Branch, Iran

2 Sapienza University of Rome, Department of Architecture and Construction, Italy E mail: Artboy3000@yahoo.com , 'E mail: eh.valipour@gmail.com

\begin{tabular}{l}
\hline A R T I C L E I N F O: \\
\hline Article history: \\
Received 08 April 2018 \\
Accepted 10 May 2018 \\
Available online 05 June 2018 \\
\hline Keywords: \\
Urban density; \\
Air Pollution; \\
Morphology; \\
Tehran Metropolis.
\end{tabular}

This work is licensed under a Creative Commons Attribution NonCommercial - NoDerivs 4.0. "CC-BY-NC-ND"

\begin{abstract}
A B S T R A C T
Today, regard for the wellbeing of the group and the earth is on the plan of most nations on the planet, and one of its imperative viewpoints is the contamination of the air and figuring out how to diminish it. Without a doubt, a standout amongst the most vital ranges that assume an unequivocal part in decreasing or expanding this parameter is the city and urban morphology. Tehran, which is viewed as the capital and vital city of Iran, has experienced this issue for a long time, and there are no legitimate arrangement found to decrease its air contamination. Then again, the city has movement from different parts of the nation consistently that makes this issue harsher. The most vital issue in such manner is the city's range, and in addition the city's extension, which decides the thickness of the city. The greater part of this must be joined by the wear and tear of a low standard, which includes a high level of contamination. The failure of the vast majority to purchase houses inside the city has made satellite towns nearby Tehran. Then again, the presence of tremendous local locations around Tehran and the area of workplaces in the downtown area are among alternate issues tended to in this investigation. This examination endeavored to utilize the explanatory expressive technique to think about the part of pressure and morphology of Tehran and its effect on air contamination and give answers for diminishing air contamination and movement.
\end{abstract}

JOURNAL OF CONTEMPORARY URBAN AFFAIRS (2019), 3(1), 38-43.

https://doi.org/10.25034/ijcua.2018.4680

www.ijcua.com

Copyright (C) 2018 Journal Of Contemporary Urban Affairs. All rights reserved.

\section{Introduction}

The city is a logical issue since its target and physical measurements in all social, monetary, physical, and spatial fields can be measured by logical criteria. Then again, the city is a spatialworldly marvel created in a specific point in space and created after some time. Urban areas are considered as an imperative piece of the spatial viewpoints of sustainability and advancement in progress in urban communities, so they can be considered as the most vital stage for economic improvement. Then again, the huge deluge of populaces into substantial urban communities and the quest for meeting fundamental human needs and urban requirements is a standout amongst the most critical worries in the present urbanization. As indicated by UN gauges, in the vicinity of 2000 and 2025, with the multiplying of the quantity of urbanists, their extent is required to increment from $47 \%$ to over $61 \%$ (Hall and Fifeffer, 2009; 35). With the fast development of the total populace and its focus in urban communities, suburbia of urban areas have been quickening and

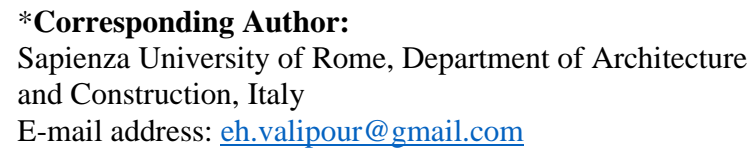


the urban arranging emergency has turned out to be across the board in many parts of the world; thus, the urban advancement worldview is serious to accomplish maintainability and social and spatial equity. Actually, the possibility of a "minimal city" was a consistent reaction to the worries of urban advancement (Tory, 1996). The growth of the city and the increase of urban density alone, in order to answer the problems, as quantitative coordinates and the qualities are ignored. What has been encountered by today's cities in Iran, including Tehran, is the quantitative growth where the development debate is less visible. In today's urbanization, high-rise buildings can be designed as one of the features of a city's view with a node that has a positive role in increasing the visual characteristics of the city. City view as the most important link of the city with the viewer is the language of a city, which induces the state of the city to the viewer. Urban views establish communication with urban viewers and have the greatest visual impact on the urban observer. Therefore, the city density and the densely populated city cannot be avoided, but there must be a way to apply these parameters correctly to make the city dynamic and least problematic.

\section{Methodology}

In this paper, the comprehensive plan for reduction of air pollution in Tehran and the pathology of its different axes have been investigated and the morphology of this city and urban density have been investigated to discuss and compare the reduction in the air pollution in the metropolis of Tehran. Given the nature of the subject and the objectives of the research, the approach to the research space is descriptive-analytic. Data collection method of initial data is documentary and library using Tehran Metropolitan Statistical Yearbooks and the urban comprehensive plan and the stations for measuring the amount of air pollution. The population of Tehran's 22 districts is surveyed by surveying the city's morphology, topography, population density, and user and vehicle evaluation. In addition, personal and public vehicles and their pollutants are also examined and classified to identify and present the main pollutants and find the appropriate solution.

\section{Dense city}

Despite the many definitions of the sustainable city, some believe that the concept of sustainability of the city is so comprehensive that cannot be converted into scientific dimensions and cannot simply be converted into concrete, short-term and executive actions. Alternatively, it may be possible to determine the stability but not able to measure it (Tabibian, 1999; 52). Nevertheless, in general, the compact city, in terms of form and scale, is a city suitable for walking, cycling and public transport, along with a congestion that encourages social interactions. In practice, this scale equals the density of streets and buildings of three or four floors in the urban areas of most English and European cities (Pourmohammadi and Ghorbani, 2003; 94). Some urban conservation researchers consider the need for less frequent travel by car, public transport support and pedestrians or bicycles associated with reduced fuel consumption as the benefits of a densely populated city. In addition, more and better access to services and facilities, increasing the efficiency of urban services are of the consequence of urban compactness (Burton, 2000; 19). Optimization of energy consumption, reduction of harmful gases by reducing the need for transportation and reducing waste of resources due to the provision of basic services with better efficiency from the state are of other advantages of the compact city (Pourmohammadi, Qorbani, 2003; 94). The urban compact structure shows the complex reality of everyday life in many successful cities, which can be applied to the pattern of radial, longitudinal, and organic cities along the paths of communication. These are the patterns of cities spread against and expansion that has been overwhelming, but Tehran has experienced some kind of controversy in this regard. On the other hand, the urban model is denser in its planning, and on the other hand, there is an increasing trend in the area of the metropolis on the surface and wide increasing urbanization has caused many traffic and pollution. The compact urban development pattern maintains appropriate levels of economic and social activities around urban and local centers, and ensures that all parts of the city - even remote areas and quieter neighborhoods - at a distance have good sources of basic transportation and urban services. It is precisely such a level of development that is felt in most urban areas of today, but due to the lack of proper management of this metropolis, there is neither good public transit nor distance of residential areas are respected for recreation facilities and, in fact, a decent city strategy, due to lack of understanding and implementation, has become a major dilemma for the city. The location or position of creating flexible policies for congestion plays an important role. There 
are certain areas where priority should be given to increasing the density of space use. Urban and transportation centers both attract more population density and more diverse use. Many recycled lands are ideal for this type of development and construction, in coordination with other sectors because of their location in cities. Municipalities can use incentives to increase congestion in designs that have high design quality in response to high-density construction needs.

\section{Building Density}

The urban texture, physically, can be seen as the accumulation of space-wise units. Here, the study of the form, in different scales, in both dimensions and in three dimensions, can be constructed as a combination of individual structures, blocks, urban areas, and entire urban texture. In addition, when considering the pattern of streets and squares, one can notice the space between these sectors. On the other hand, the growing population of large cities, the relentless invasion of rural populations, the concentration of power centers and welfare facilities and job opportunities, the inadequacy of laws and mismanagement are among the factors that put the cities at serious risk. With the development of environmental wastes and the decline in the general level of living, especially in urban societies, over the past two to two decades, the sustainable development approach was identified by the United Nations as the most important issue of the last decade of the twentieth century (Kazemi, 2001). The density of the number or area (each element examined) in a space (or level) is called the density of that element in that space or surface (Mashhdi, 2010; 9). Demographic density is obtained by dividing the total population of the target area into its built-in level. In this definition, the calculated level does not include the scale of the city. Building density refers to as the total building area to the total area of the building's base (Azizi, 2004; 21). Demographic density is a planning language for urbanization, whereas congestion is the practical and operational language of demographic density in urban planning. Increasing or decreasing construction density in housing and residential plans has a significant impact on the production of infrastructure for housing and building (Azizi, 2009; 5). Growing high-rise growth has led to the emergence of squeezed cities with their own disadvantages and advantages. For example, high-rise makes vertical population denser and therefore reduces traffic, but on the other hand, it affects environmental factors such as shading and not reaching the neighboring units. However, it should be noted that high-rise buildings as indicators of high visibility can be considered as symbolic elements, and, on the other hand, they can deprive the visibility of the existing urban signs and face. Therefore, the location of high-rise buildings, if properly selected and located in necessary places, will deepen the sense of location and direction in the city's inhabitants and can be used as factors in the identification of the city and in different parts of it.

\section{Air pollution and Tehran metropolis}

Pollution has become one of the main challenges countries face. In such a way that countries, in addition to policies and actions within their borders, are also pursuing a policy of pollution in the international arena. Among the examples of contamination, air pollution, which is more prevalent due to its nature, is more or less perceptible in most parts of the world. Undoubtedly, production and spread of pollution are a function of the process of economic growth and development of the countries. Air pollution is one of the greatest environmental problems in the world that threatens the health of living creatures. Solids, liquids or gases released from natural resources or because of human activities in the air damage the health of humans, animals and plants and the balance of ecosystems (Dimitriou, 2007: 24). A survey is conducted on 12 countries, 25 cities and a population of 39 million, where the death toll from air pollution was 10,000. The most important dangers from air pollution are human health due to NOx, SO2 and dusts. Contaminants from contaminated materials, in addition to affecting human life, endanger the ecosystem's surroundings by transferring into disrupting water and soil and endangering the life of plants. In 2013, Tehran was named the 19th most polluted city in the world. Tehran's air pollution has caused a 60 percent increase in respiratory illnesses and a reduction in average life expectancy of residents up to five years. According to estimates, the death toll from air pollution in Tehran is about 27 people a day, and about 4,000 people a year. The number of clean days from March to September 2016 decreased to 8 days, while in the same periodof the previous year it was 29 days. Therefore, Tehran is one of the most polluted cities in the world (1993). Graedel and Crutzen stated that the major part of pollutants released from internal combustion engines are hydrocarbons, carbon monoxide, nitrogen oxides, and oxides of sulfur, particles 
and pollutants (Fshinehnejad, 2004) along the main pollutants in engines are combustion of gasoline sparkings of hydrocarbons. These three pollutants in the normal operating conditions of the engine have the largest share in the emissions of gasoline engines, with $90 \%$ of these gases through the medium motor vehicles and cars, and the remaining $10 \%$ from homes, waste incinerators and small workshops in the city (Rafipour, 2000).

\section{Morphology, Topography and pollutants in Tehran metropolis}

high velocity and can contribute to the outflow of pollutants from the city (Kermani, 2003). On the other hand, Tehran has an area of about 800 square kilometers. There are more than 7,000 industrial units in Tehran, 30\% in the West, $54 \%$ in the South, and $16 \%$ in East Tehran. According to the study, the most important factors affecting Tehran's air pollution were the population of more than 12 million Tehran in the day and about 9 million people per night, the specific topographic climate situation, and population density. Moreover, the reason are industry and urban transport network, inappropriate quality of diesel fuels and high

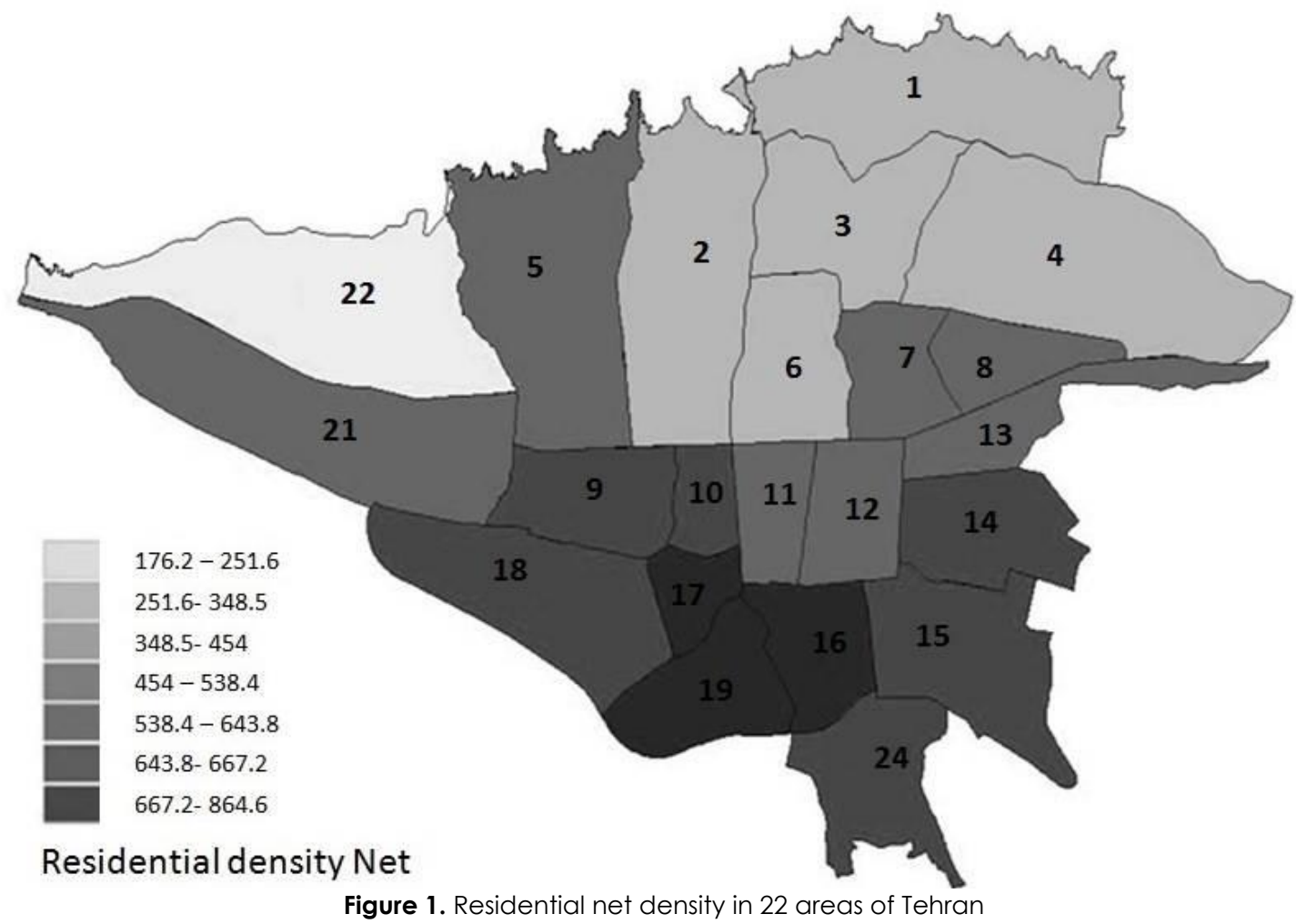

Tehran is located on the slopes of the Alborz Mountains and the northern margin of the central desert in the plain enclosed to the north by these mountains. From north to south, on the slopes of Shemiranat Mountains, $10 \%$ to $15 \%$ of Tajrish to the hills of Abbasabad with a mean inclination of $3 \%$ to $5 \%$ from Abbasabad to Engelab Street $2 \%$ and from the center of Tehran to the suburbs $1 \%$. The length and width of this city is at its highest is 50 and $30 \mathrm{~km}$. Mountain winds dominate the plain and plain to the mountains and merely cause the transfer of pollutants from the northwest to the south east and from the south to the north, and the northern mountains prevent the release of pollutants. In addition, $70 \%$ of Tehran's winds are weak and have variable directions, and only $30 \%$ of the rest are west, northwest, and southwest of Tehran, which have a relatively levels of sulfur in diesel production, elimination of lead in gasoline and replacement of more polluting substances with benzene.

The population growth rate is not consistent with the growth of green space, and the per capita green space inhabitants of Tehran are far below the international standard, which is the cause of air pollution. One of the effective factors in increasing the concentration of this pollutant in Tehran is the presence of moving and fixed pollution sources and a specific topography of the city. 


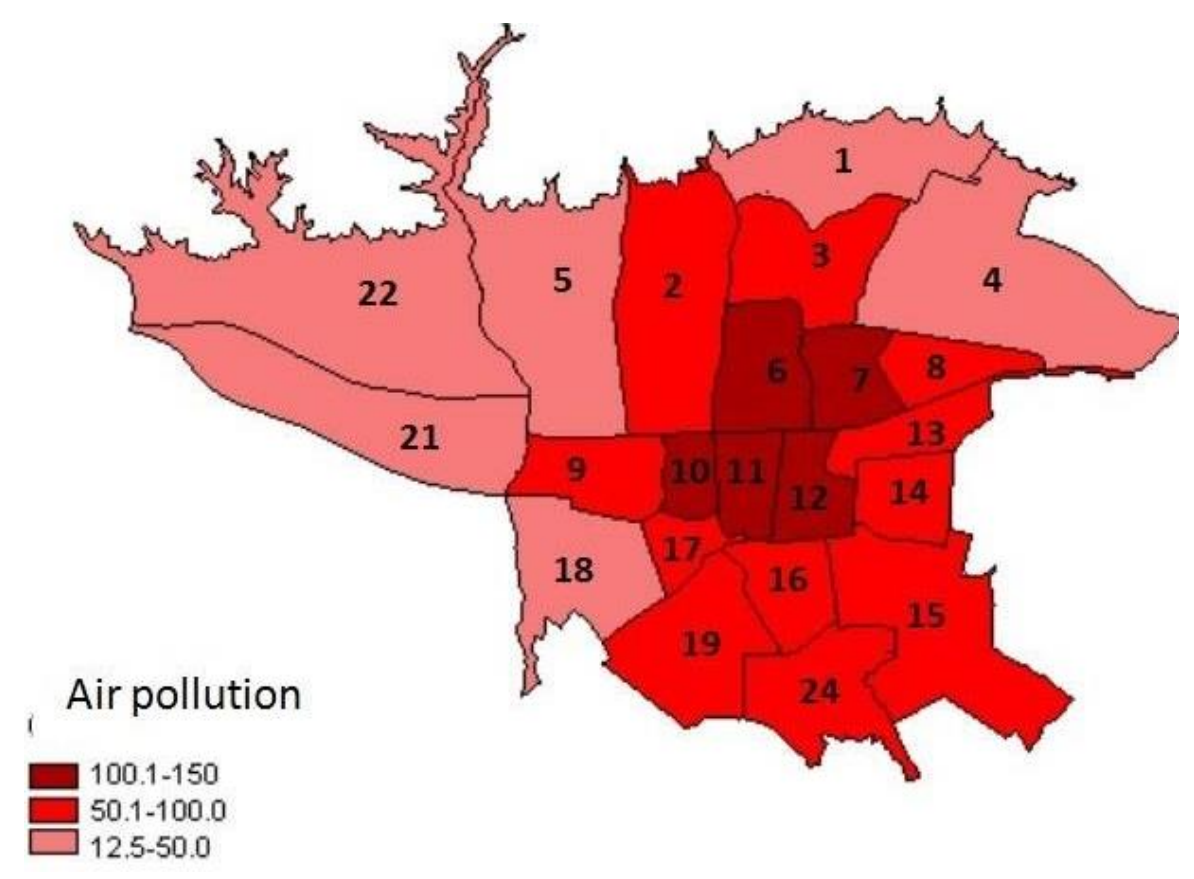

Figure 2. Distribution of air pollution (carbon monoxide) in Tehran regions (2002-2005); sources: literature by Mohammad Hossein Gholizadeh et al.

According to Figures (1) and (2) it can be concluded that living in southern Tehran is more densely populated but due to the density of government offices, markets and other businesses in the city center, the invasion of this area causes the highest level of pollution in this area. On the other hand, as the capital and center of the largest metropolitan complex of Iran over the past decades, Tehran has attracted a lot of population, privileges, and facilities and, consequently, many problems. The results of the comprehensive evaluation model show that in Tehran in 1996, only $53.3 \%$ of the urban environment was desirable. In the comprehensive plan of the Tehran metropolitan area, the issue of preventing the expansion of the metropolitan suburbs under the title "Organization and maintenance of the area and preventing any expansion of the city" has been mentioned. Therefore, it seems that the form of a densely populated city has been selected as a desirable form in planning for sustainability Tehran. However, according to Figures 1 and 2, it can be easily understood that the distribution of the population and the concentration of organizations, departments and ministries in the city center have led to a massive amount of urban traffic, which is more often created by private cars and the resulting pollution is among metropolitan problems of Tehran. The lack of proper planning has caused pollution, traffic and other environmental problems in the city. The air of Tehran until March 21, 2015 was 16 days and in 2013 it only had a clean 3 days. Most pollutants in Tehran metropolitan area according to the surveys are as follows:

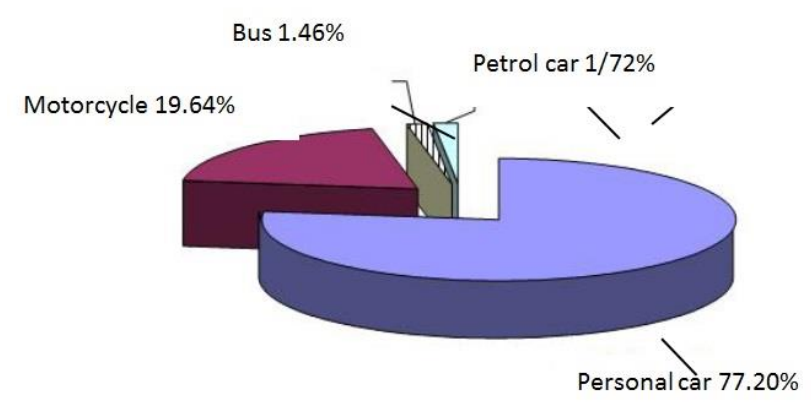

Figure 3. The contribution of different transport system groups to the pollution of the moving air resources of Tehran in 2004, Source: Writers

What is clear from the figures above is that the lack of urban densities in Tehran has not only contributed to the removal of urban problems, but also has aggravated these problems, and Tehran's morphology has been ineffective and inadequate for this reason. Therefore, the metropolitan managers of the metropolitan area should seek new thinking as soon as possible to prevent it before the disaster.

\section{Conclusion}

In order to reduce the amount of pollutants in Tehran, it is necessary to collect and manage resources worn out and non-standard cars. In addition, expanding public transportation, improving the monitoring and culture development process in the community can also reduce pollution. Making a proper technical inspection, resulting in correction of technical defects in the vehicle, is another way of reducing pollutants. On the other hand, heavy taxes have to be levied on private cars entering the traffic and city center area, with 
the highest volumes of pollution would make public transport more welcomed. In this regard, the sale of a traffic plan that even happens on a daily basis should be stopped as soon as possible, as many vehicles with this design do not have the minimum environmental standards. On the other hand, appropriate loans must be provided for the removal of worn out vehicles, and the need for domestic and legal follow-up for the production of built-in vehicles must be carried out in accordance with international standards to minimize fuel consumption, air pollution and energy depreciation. Updating the public transport fleet, such as in-city buses, the construction of new bus and metro lines that cover the whole city should be carried out as well At the core of urban design should also be noted that the sale and granting density to the city center should be carefully and strictly carried out and sell bulk density in the West that Tehran be appropriate to reduce pollution should be minimized to lobby conditioning the air is unobstructed and reduces the pollution of the city. Another way is the fair distribution of recreational and service facilities at the city level in order to reduce the volume of traffic. Moreover, the concentration of offices, ministries, and government agencies in the city center, and some of them that have the least link with the rest of the world have moved from that location to other locations. Eventually, the city's greenhouse has to be increased, so it is close to having a clean city and pollution.

\section{Acknowledgement}

This research did not receive any specific grant from funding agencies in the public, commercial, or not-for-profit sectors.

\section{Conflict of interests}

The authors declare no conflict of interest.

\section{References}

Pourmohammadi, M.R. and Gharbani, R. (2003). Paradigm Dimensions and Strategies for Density of Urban Spaces. Quarterly Journal of Humanities, Vol.6, No. 29, pp. 85- 107.

Kazemi, $M$ and Mohammadi, M. (2001). "Sustainable Urban Development, Concepts and Perspectives", Quarterly Journal of Geographic Research, No. 62

Tabibian, M. (1999). Determination of Sustainability Indicators and their Representation in the Environment". Journal of Environmental Studies, Vol. 25, No. 24, pp. 12-12. https://www.journals.elsevier.com/journal-ofenvironmental-sciences

Azizi, M.M. (2009). The role and place of building density in urban development, Proceedings of the first construction seminar in the capital https://bipublication.com/files/20160230.pdf

Azizi, M.M. (2004). Density in Urban Planning Second Edition, Tehran: Tehran University Press. http://press.ut.ac.ir/

Gholizadeh, M.H. and Farajzadeh, M., and Mohammadi, M. (2009), Relationship between air pollution and mortality in the population of Tehran, Hakim Research Journal, Summer 88, Volume 12, Number 2, pp. 65-71. https://www.ncbi.nlm.nih.gov/pmc/articles/PMC 5859399/

Mashhadi, S. (2010). Population density and construction in Shohreh., Tehran: Masinaei Publishing. http://jmre.journals.ikiu.ac.ir/

Farshinehnezhad, M.R. (2004), "Introduction to Environmental Issues," Adineh Publication. http://press.ut.ac.ir/

Rafipour, (2000), The Swedish Environmental Protection Agency. "Final Report on Formation of a Basic Information Item for the Study of Air Pollution in Cities", Research Center for Meteorology and Geosciences. https://www.naturvardsverket.se/Documents/pu blikationer6400/978-91-620-6784-

7.pdf?pid=21 182

Hall, P. and Fifer, O. (2009). 21st century urban future. Safai, Venus Tehran: Iranian Consulting Engineers Society. https://www.ncbi.nlm.nih.gov/pmc/articles/PMC 4898840/

Kermani, M. (2003) "Investigation of TSP and 10 PM values and composition of their constituent materials in the air of Tehran Shariati Hospital", Master's Degree in Environmental Health Engineering, School of Public Health and Research Institute of Health Research, Tehran University of Medical Sciences. http://press.ut.ac.ir/

Tory, P.N. (1996). Urban Consolidation and the family, in the Compact City: A Sustainable Urban Formss, London:E and Fn Spon, and Imprint of Chapman and Hall. https://www.researchgate.net/publication/2489 74140_Three_Challenges_for_the_Compact_City as a Sustainable Urban Form Household Con sumption_of_Energy_and_Transport_in_Eight_Resi dential_Areas_in_the_Greater_Oslo_Region

Burton, E. (2000). the potential of the compact city for promoting social equity Achieving sustainable urban form: Spon press. https://www.researchgate.net/publication/3131 03443 The potential of the compact city for $\mathrm{p}$ romoting_social_equity

Dimitriou A, Christidou V. (2010) . Pupils' understanding of air pollution. Journal of Biological Education. 42(1):24-29. https://doi.org/10.1080/00219266.2007.9656103 